CLINICAL STUDY

\title{
Final height in young women with Turner syndrome after GH therapy: an open controlled study
}

\author{
Ze'ev Hochberg and Zvi Zadik ${ }^{1}$ \\ Department of Pediatrics, Rambam Medical Center, Haifa, Israel and ${ }^{1}$ Pediatric Endocrine Unit, Kaplan Hospital, Rehovot, Israel \\ (Correspondence should be addressed to Z Hochberg, Faculty of Medicine, POB 9697, Haifa 31096, Israel)
}

\begin{abstract}
GH therapy has been applied to patients with Turner syndrome for over a decade, but small sample size, delayed initiation of therapy into adolescent age and comparison with historical control subjects limit the usefulness of these studies for appraisal of the effect of GH on final adult height. We report 49 young women with Turner syndrome who completed a clinical trial in an open, non-randomized, agematched controlled study of GH, given as daily s.c. injections at a weekly dose of $8.2 \mathrm{mg} / \mathrm{m}^{2}$ for $1.9-7.5$ years. Final height was defined as the measurement taken 2 years or more after height velocity declined below $2 \mathrm{~cm}$ /year and after a bone age of 15 'years'. The gain in height was evaluated in three ways. The mean final height gain, compared with the control group, was $4.4 \mathrm{~cm}$. When corrected for the projected height at inception of therapy, the mean gained height was $5.3 \mathrm{~cm}$ above the control group. Shorter girls showed better response to GH then did taller girls. After correcting for parental height, the mean gain was $4.7 \mathrm{~cm}$. The adult height of the GH-treated Turner women was significantly correlated with the target height, whereas no such correlation was obtained for control untreated women. Furthermore, no correlation was observed between height gain and the age or duration of GH therapy, or the age of inception of estrogen replacement therapy. It is concluded that GH therapy augments final height of girls with Turner syndrome by a mean $4.4-5.3 \mathrm{~cm}$, depending on the method of evaluation, and that shorter girls may be preferred candidates for such therapy. GH therapy can be initiated after age 10 years and there is no reason to delay estrogen therapy beyond the age of 12 . Indirect evidence suggests that high-dose GH therapy may surmount a pathophysiological resistance in the GH-IGF-I axis.
\end{abstract}

European Journal of Endocrinology 141 218-224

\section{Introduction}

Early reports of growth hormone (GH) therapy in girls with Turner syndrome, using doses that are used in the treatment of children with GH deficiency, revealed poor growth acceleration $(1,2)$. After high-dose GH therapy was instituted, therapy was estimated to be effective, as inferred from short-term growth acceleration and final height projections. Results of long-term growth and final height after $\mathrm{GH}$ therapy in girls with Turner syndrome are now available from several studies. These reports are mostly based on small sample sizes, variable ages of GH initiation and historical controls, and thus, as might be expected, vary considerably from study to study. Whereas some reports show only a small gain in height $(3,4)$, others claim a significant improvement in adult height (5-7). It is quite likely that other factors also account for these variations, including ethnic and genetic differences (8) and differences in the age of initiation of estrogen replacement therapy. Ever since the availability of the currently used recombinant
GH therapy, significant growth acceleration, already observed after short-term treatment, created a bias in favor of therapy and prevented the design of controlled studies $(7,9)$. In the leading study of Rosenfeld et al. (7), the randomized control group was maintained without treatment only for the initial 12-24 months, after which GH therapy was initiated. As a result their final heights are compared with historical control subjects (7). Only later were randomized clinical trials initiated in the US and Canada, but these results are still pending.

We report a controlled trial of GH therapy in 49 patients with Turner syndrome. In the design of the present study, a placebo control group was deemed unnecessary, since placebo treatment was previously shown to have no effect on growth (1). An agematched open untreated control group was followed for growth. In the present study GH therapy exerted greater effects on the shorter patients, but overall, there was a great disparity in final height and it was poorly correlated with therapeutic modality and estrogen replacement. 


\section{Patients and methods}

The subjects of the present report are 49 young women with Turner syndrome who completed the clinical trial, out of 50 who started it in two centers, each center treating half of its patients. This number of patients was calculated to have the statistical power for significant results. The karyotype distribution was: 25 women with 45,XO, 15 with 45,XO/46,XisoXq, 4 with 45,XO/ $46, \mathrm{XX}$ and 5 with $45, \mathrm{XO} / 46, \mathrm{XY}$. The short-term growth response to $\mathrm{GH}$ therapy was previously reported for the first ten patients enrolled (10). The study protocol was approved by the Helsinki Committees of the Rambam Medical Center, the Kaplan Hospital and the Israel Ministry of Health. This clinical trial was supported by a pharmaceutical company only in as much as $\mathrm{GH}$ was donated for the initial 1 or 2 years of therapy.

All the patients with Turner syndrome of these two clinics, with an age limit of $7-14$ years and a bone age $<12$ 'years' were divided openly into a GH treatment group and a control age-matched group. After a thorough explanation of the experimental nature of this treatment, the parents' approval or refusal to participate in a new treatment trial was the only criterion for selection. Though open and unrandomized, the clinical characteristics of the two groups were similar and statistically not different from each other, as shown in Table 1.

The treatment protocol included the following parameters. Recombinant GH (BioTropin, BioTechnology General Ltd, Rehovot, Israel, and Humatrope, Eli Lilly, MN, USA) was given as daily s.c. injections at a weekly dose of $8.2 \mathrm{mg} / \mathrm{m}^{2}$. Therapy was initiated at age $10.7 \pm 1.4$ years (mean \pm S.D., range $7.9-14.1$ years) in prepubertal girls and before estrogen replacement therapy, and continued for $5.1 \pm 1.9$ years (range $1.9-$ 7.5 years) until commencement of a bone age of 14 'years'. Ethinyl estradiol replacement was added 2 years or more after GH initiation; the actual age was decided individually by the patient and parents, but it was started no earlier then at 12 years old. The initial dose of $50 \mathrm{ng} / \mathrm{kg}$ was increased 12 months later to $100 \mathrm{ng} / \mathrm{kg}$ and then again to $200 \mathrm{ng} / \mathrm{kg}$ after a further 12 months. Final height was defined as a measurement taken 2 years or more after height velocity declined below $2 \mathrm{~cm} /$ year and after a bone age of 15 'years' was repeated (Greulich and Pyle method).

Heights are expressed as standard deviation scores (SDS) of the general population, calculated from the Tanner growth charts (12) and from the Ranke's Turner growth charts (11). The latter were also used for adult height projection. Results are expressed as mean \pm S.D. Student's $t$-tests compared means of the control against treatment population, after both were shown to be normally distributed.

\section{Results}

The gain in height attributed to therapy was evaluated in three ways: final height; gain over projection; and height deficit.

For final height, whereas the mean initial height and growth velocity at age 10.7 years was similar for the $\mathrm{GH}$ and the control groups, being 120.6 and $121.7 \mathrm{~cm}$ respectively, final height was $147.3 \pm 4.9$ and $142.9 \pm 5.1 \mathrm{~cm}$ respectively. The mean gain in height of the GH-treated group was $4.4 \mathrm{~cm}(P<0.005)$ (Table 1).

To assess gain over projection, to allow for individual assessment of height gain, Fig. 1 shows the adult

Table 1 Clinical characteristics of the 49 young women with Turner syndrome who were the subjects of this study. Mean \pm S.D. (range). No significant difference was observed between untreated and treated groups for the first five sets of parameters studied $(P>0.05)$.

\begin{tabular}{|c|c|c|c|c|}
\hline \multirow[b]{2}{*}{$\begin{array}{l}\text { Mother's height }(\mathrm{cm}) \\
\text { Father's height }(\mathrm{cm}) \\
\text { Target height }(\mathrm{cm})\end{array}$} & \multicolumn{2}{|c|}{ Control untreated $(n=24)$} & \multicolumn{2}{|c|}{ After GH treatment $(n=25)$} \\
\hline & $\begin{array}{l}161.3 \pm 7.3 \\
172.7 \pm 5.8 \\
163.5 \pm 5.8\end{array}$ & $\begin{array}{l}(147.2-174.1) \\
(162.1-180.2) \\
(152.5-173.5)\end{array}$ & $\begin{array}{l}159.6 \pm 5.7 \\
174.0 \pm 5.3 \\
163.3 \pm 4.8\end{array}$ & $\begin{array}{l}(151.1-170.3) \\
(162.2-183.1) \\
(156.5-173.0)\end{array}$ \\
\hline $\begin{array}{l}\text { Study initiation age (years) } \\
\text { Study initiation bone age ('years') } \\
\text { Height SDS TW standards }{ }^{1} \\
\text { Height SDS TS standards }{ }^{2} \\
\text { Growth velocity (TW) SDS } \\
\text { BMI SDS } \\
\text { Projected height (cm) }\end{array}$ & $\begin{array}{r}10.7 \pm 1.4 \\
9.4 \pm 0.9 \\
-2.2 \pm 1.4 \\
-0.2 \pm 1.5 \\
-2.1 \pm 0.5 \\
-0.4 \pm 0.6 \\
143.5 \pm 4.2\end{array}$ & $\begin{array}{c}(8.5-14.0) \\
(8.0-10.5) \\
(-3.5--1.0) \\
(-1.4-+1.7) \\
(-3.2--1.0) \\
(-1.3-+1.1) \\
(134.5-153.5)\end{array}$ & $\begin{array}{r}10.7 \pm 1.4 \\
9.3 \pm 1.0 \\
-2.4 \pm 1.1 \\
-0.5 \pm 1.3 \\
-2.1 \pm 0.4 \\
-0.1 \pm 1.2 \\
142.6 \pm 5.2\end{array}$ & $\begin{array}{c}(7.9-14.1) \\
(7.0-11.3) \\
(-3.3--1.2) \\
(-0.9-+1.1) \\
(-3.0--1.2) \\
(-1.8-+3.8) \\
(133.0-150.0)\end{array}$ \\
\hline $\begin{array}{l}\text { GH therapy duration (years) } \\
\text { Estrogen replacement age (years) } \\
\text { Spontaneous puberty }(n) \text { (Tanner B2 age) }\end{array}$ & $\begin{array}{r}- \\
13.4 \pm 0.8 \\
3\end{array}$ & $\begin{array}{l}- \\
(12.0-15.2) \\
(11.0-12.5)\end{array}$ & $\begin{array}{r}5.1 \pm 1.9 \\
13.2 \pm 1.0 \\
5\end{array}$ & $\begin{array}{c}(2.6-7.5) \\
(12.0-16.2) \\
(11.5-12.1)\end{array}$ \\
\hline $\begin{array}{l}\text { Final height }(\mathrm{cm}) \\
\text { Final age (years) }\end{array}$ & $\begin{array}{r}142.9 \pm 5.1 \\
19.6 \pm 2.9\end{array}$ & $\begin{array}{c}(133.0-154.6) \\
(17.0-24.0)\end{array}$ & $\begin{array}{r}147.3 \pm 4.9 \\
18.1 \pm 1.0\end{array}$ & $\begin{array}{c}(139.0-154.0) \\
(16.9-20.0)\end{array}$ \\
\hline $\begin{array}{l}\text { Gain in height }{ }^{3}(\mathrm{~cm}) \\
\text { Height deficit }^{4}(\mathrm{~cm})\end{array}$ & $\begin{array}{l}-0.6 \pm 2.2 \\
20.7 \pm 6.0\end{array}$ & $\begin{array}{l}(-6.0-2.2) \\
(7.1-36.5)\end{array}$ & $\begin{array}{r}4.7 \pm 2.9 \\
16.0 \pm 4.6\end{array}$ & $\begin{array}{r}(-0.4-10.4) \\
(8.0-25.3)\end{array}$ \\
\hline
\end{tabular}

${ }^{1}$ Tanner-Whitehouse (12). ${ }^{2}$ Turner syndrome (11). ${ }^{3}$ Final height - projected height. ${ }^{4}$ Target height - final height. 
height as a function of projected height in control and GH-treated girls. The gain in height was calculated for each subject as [final height-projected height]. In the control group, projected height reached the final height within $\pm 2.5 \mathrm{~cm}$, in 21 of 24 patients and deviated by $3.5-6.0 \mathrm{~cm}$ in the other three. The height gained by the GH group averaged $5.3 \mathrm{~cm}$ more then that by the controls $(P<0.005)$ (Table 1$)$.

For height deficit, adjustment for parental height was made by calculation of the target height, and height deficit was calculated as [target height-final height]: it was $20.7 \pm 6.0 \mathrm{~cm}$ in the control group (range $7.1-36.5 \mathrm{~cm}$ ) and $16.0 \pm 4.6 \mathrm{~cm}$ in the $\mathrm{GH}$ group (range $8.0-25.3 \mathrm{~cm}, P<0.01$ ), and the mean gain was $4.7 \mathrm{~cm}$ (Table 1). The adult heights of the women who had been treated with GH were significantly correlated with the target height $(r=0.553, P<0.005)$, unlike the control untreated Turner women $(r=0.383, P=0.065$, Fig. 2A). Final heights of untreated patients did not correlate with their
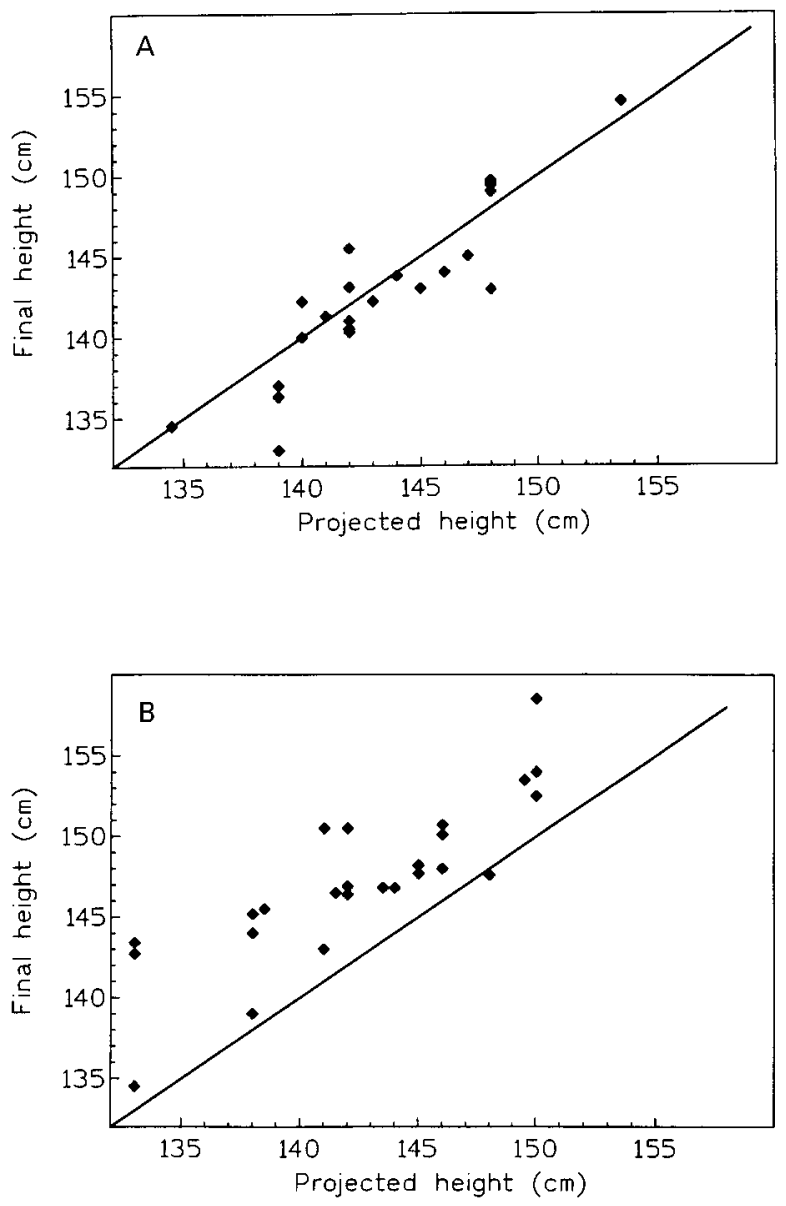

Figure 1 Final height as a function of pretreatment projected height in young women with Turner syndrome. (A) Twenty-four untreated women, $r=0.818, P<0.0001$; (B) 25 women after $\mathrm{GH}$ treatment, $r=0.836, P<0.001$. The diagonal line indicates the projected height as the final height. mothers' $(r=0.323, P=0.123)$ or with their fathers' heights $(r=-0.123, P=0.554$, Fig. 2B and $C)$. On the other hand, the adult height of treated patients correlated significantly and to a similar extent with both their mothers' $(r=0.484, P<0.02)$ and their fathers' heights $(r=0.488, P<0.02$, Fig. $2 \mathrm{D}-\mathrm{F})$.

Grouping the patients according to their karyotype showed a mean height gain of $5.7 \mathrm{~cm}$ in the $45, \mathrm{XO}$ patients, $3.6 \mathrm{~cm}$ in the $45, \mathrm{XO} / 46, \mathrm{XisoXq}, 4.8 \mathrm{~cm}$ in the $45, \mathrm{XO} / 46, \mathrm{XX}$ and $2.4 \mathrm{~cm}$ in the $45, \mathrm{XO} / 46, \mathrm{XY}$. These differences were statistically insignificant.

In an attempt to determine retrospective therapeutic factors that might have influenced the success of $\mathrm{GH}$ treatment, we determined the correlation between the gain in height (defined above) and several treatment parameters. We also determined the correlations between the height deficit and these treatment parameters, but since they were essentially identical to those for gain in height, they are not shown. The negative correlation of gain in height with the pretreatment projected height was close to significance $(r=0.374$, $P=0.066$, Fig. 3). As expected, correlation with pretreatment height SDS gave identical results. Thus, shorter girls show better response to $\mathrm{GH}$ than do taller girls. The projected height of control untreated girls did not correlate with the deviation of final height from projected height (Fig. 3).

We then correlated the age of treatment, its duration and the age of estrogen initiation with the gain in height. None of these variables bear any significant correlation (Fig. 4). Furthermore, the degree of obesity (calculated as body mass index (BMI) SDS for age) also did not correlate with the gain in height after $\mathrm{GH}$ therapy $(P>0.1$, data not shown).

Overall, in spite of the relatively high doses administered, GH therapy was tolerated well, with no clinically apparent untoward effects. Hyperinsulinemia with normal glucose tolerance was observed in most patients in whom it was looked at (Z Hochberg, unpublished observation).

\section{Discussion}

A decade or more has evolved since recombinant $\mathrm{GH}$ became available on a large scale and we now can evaluate final height results of GH therapy in Turner syndrome. Since results of the larger American controlled study are still pending, we hereby present a controlled study of a significant size. The results show a gain of adult height that is variable, ranging from no gain at all to over $10 \mathrm{~cm}$ (average $4.4-5.3 \mathrm{~cm}$, depending on the method used) when compared with the control group. These results are similar in magnitude to those in the interim report of the Canadian open controlled study (13), where a dose of GH that was $10 \%$ higher than the one used here was administered and there was a reported mean gain of $5 \mathrm{~cm}$. These results, however, show a smaller effect than the Genentech 

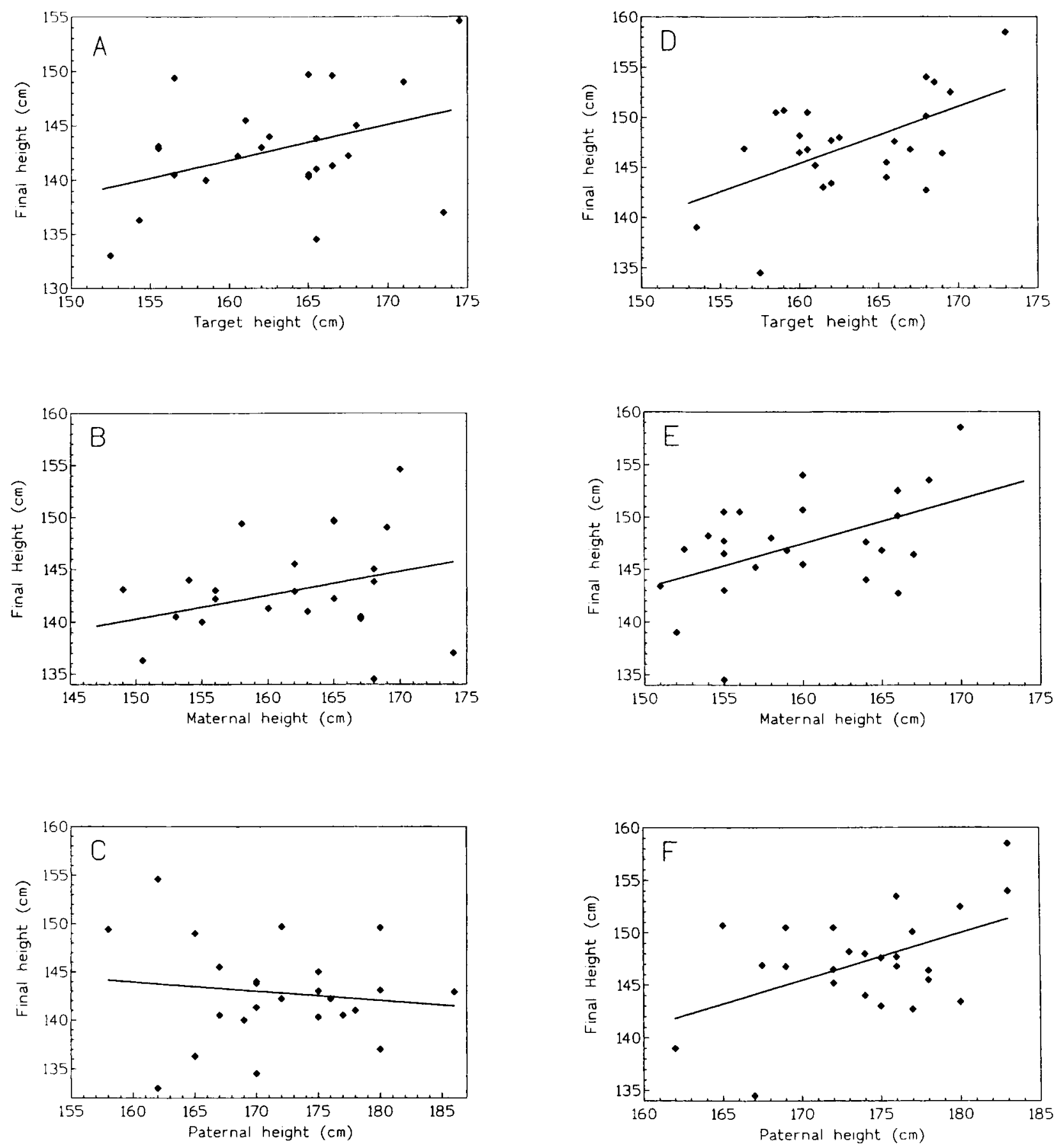

Figure 2 Final height as a function of target height $(A$ and $D)$, maternal height ( $B$ and $E)$ and paternal height $(C$ and $F)$ in young women with Turner syndrome in 24 control untreated women (A-C), and in 25 women after GH treatment (D-F). (A) $r=0.383$, $P=0.065$; (B) $r=0.323, P=0.123$; (C) $r=-0.123, P=0.554$; (D) $r=0.553, P=0.004$; (E) $r=0.484, P=0.014$; (F) $r=0.488, P=0.013$.

uncontrolled study (7), where a dose that was $37 \%$ higher then the one used here was administered and there was a reported mean gain of $7.4 \mathrm{~cm}$. A Greek controlled study reported no significant improvement in final height, probably since the mean age of treatment initiation was high, at 12.5 years (14).

The study design did not include a placebo or randomized control group for ethical and practical 

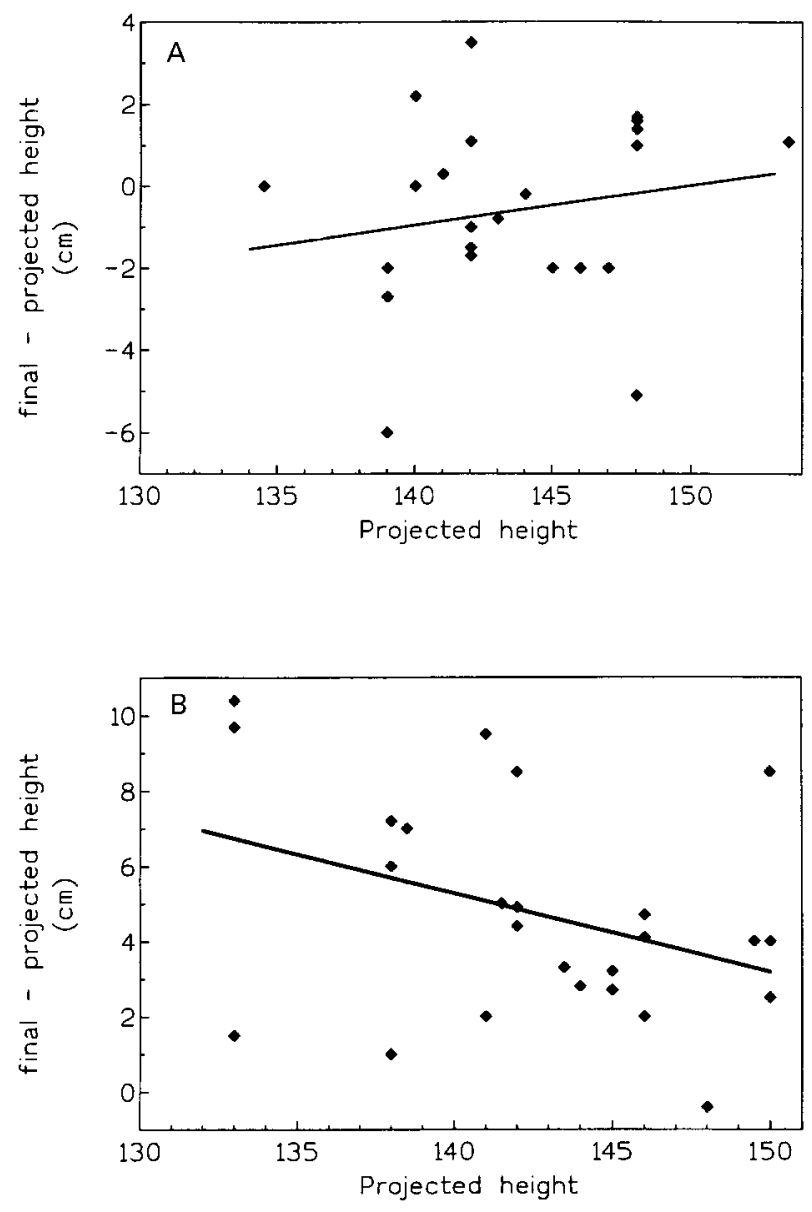

Figure 3 Gain in height as a function of pretreatment projected height in young women with Turner syndrome. (A) Twenty-four untreated women, $r=0.185, P>0.1$; (B) 25 women after $\mathrm{GH}$ treatment, $r=-0.374, P>0.05$.

reasons. However, the auxological and demographic data for the treated and untreated groups at inception of therapy were comparable. In untreated controls the divergence of the final heights from their projected height emphasizes the limitations of height prediction methods. The validity of that conclusion is reinforced by the fact that these methods are based on only a small number of observations (15). The comparably less demanding design of the current study allowed for a study that was relatively free of industry support and completely free of its influence. This has been suggested to induce a bias in favor of publication of uncontrolled positive results, often in non-peer-reviewed articles $(16,17)$.

Analysis of results according to karyotype has previously shown that it has no influence on height $(5,8)$. The impression gained here by $t$-test supported this contention, yet grouping the patients into such small groups had a limited statistical power.

Parental height correlated only poorly with nontreated final height, as previously suggested by some
$(6,8)$ but not by others $(18)$. It cannot be excluded that increasing the sample size might have produced a stronger correlation. It was interesting to note that this correlation was significantly better in women who had been treated with GH. This implies that GH treatment may surmount a physiological deficit or resistance in the GH-insulin-like growth factor-I (IGF-I) axis. Indeed, physiological doses of $\mathrm{GH}$ are ineffective in the treatment of Turner syndrome $(1,2)$. The dose of $\mathrm{GH}$ required to accelerate growth in Turner syndrome is larger then that used for $\mathrm{GH}$ deficiency or for idiopathic short stature, suggesting some resistance along the GH-IGF-I axis. Whereas serum GH and IGF-I are generally normal in Turner syndrome, we have recently demonstrated decreased sensitivity to GH and IGF-I of lymphocytes and monocytes in patients with this syndrome (19). Nevertheless, this would account for only a small part of the mechanism underlying growth retardation in Turner syndrome, since the final height is only partly restored by GH therapy. Since in Turner syndrome, $70 \%$ of patients have lost their paternal $\mathrm{X}$ chromosome (20), we wanted to test the relative impact of paternal versus maternal height. In fact, heights correlated significantly and to a similar degree with final height after $\mathrm{GH}$ therapy, but not in untreated patients. Earlier studies have variously reported that the patient height correlated to a similar extent (21) with maternal and paternal height with a somewhat better maternal correlation (22) or paternal correlation (8). It is likely that in the study reported here the sample size may not be large enough to expose the $70 \%$ of patients who lose their paternal X chromosome.

It is of practical and economical importance that the final height did not correlate with age at GH initiation or treatment duration, as previously suggested by some $(3,6,13)$ and disputed by others (18). It is also consistent with the well-characterized waning in the effects of $\mathrm{GH}$ therapy during the course of $\mathrm{GH}$ treatment. Thus, based on this prospective controlled study of 49 women, we can see no justification for initiation of GH therapy in young girls with Turner syndrome and for carrying it on for many years. It would seem more straightforward to initiate treatment at the age of 10-11 years and to continue for 3-4 years. Initiation of $\mathrm{GH}$ treatment at a younger age, and its termination before final height has been attained, may introduce catch down growth after withdrawal of therapy, as shown for children with idiopathic short stature (23).

The timing of estrogen replacement has been an issue of much debate in the management of Turner syndrome patients. Previous recommendations for late estrogen replacement were based either on theoretical considerations of the known role of estrogen in advancing bone maturation (6) or on uncontrolled studies where estrogen was given late and which showed a better final height outcome $(5,7)$. In retrospect, the decision to base the timing of estrogen 

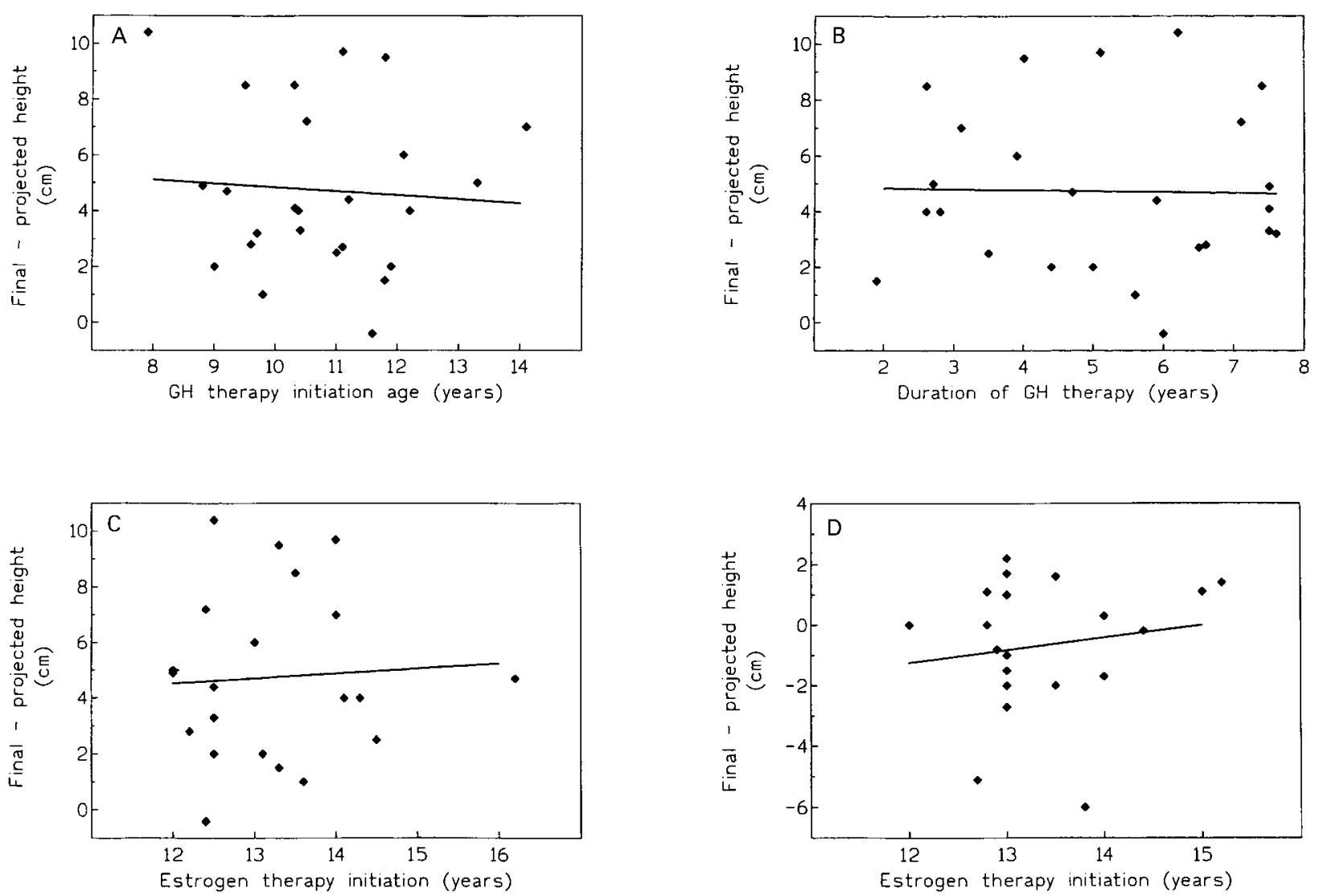

Figure 4 Gain in height as a function of the age at initiation of GH therapy (A), the duration of GH therapy (B), and the age at initiation of estrogen replacement therapy $(C$ and $D)$ in young women with Turner syndrome. All correlations are not significant.

replacement on the patient's wishes seems justified, both in terms of the individual needs and in terms of the lesson learnt from the correlation analysis. Retrospective analysis of the present study, based on results from these 49 women, shows no correlation between height gain and the age at which estrogen replacement was initiated, provided that this was beyond the age of 12 years. Indeed, most patients express the wish to develop puberty along with their class mates and the present findings show that starting very-low-dose estrogen at the age of 12 , with a slow increase in dose, does not influence final height.

Finally, the negative correlation observed between the height SDS of GH-treated patients and the gain in height is consistent with our view of who should be treated with GH. An average gain of $4.4-5.3 \mathrm{~cm}$ in final height, depending on the method used for appraisal, may not justify a long-term and costly treatment with supraphysiological doses of GH. However, the selection of patients, based on their initial low height SDS, seems to be justified with the shorter girls, and proves more beneficial in such individuals.

\section{Acknowledgements}

Recombinant $\mathrm{GH}$ was provided for some of the patients for some of the time by Eli Lilly, Israel and by BioTechnology General, Israel. We are indebted to Dr Ronnie Barkey for his constructive comments.

\section{References}

1 Tanner JM, Whitehouse RH, Hughes PCR \& Vince FP. Effect of human growth hormone treatment for 1 to 7 years on growth of 100 children, with growth hormone deficiency, low birth weight, inherited smallness, Turner's syndrome and other complaints. Archives of Disease in Childhood 197146 745-782.

2 Butenandt $\mathrm{O}$. Growth hormone deficiency and growth hormone therapy in Ullrich-Turner syndrome. Klinische Wochenschrift 198059 99-101.

3 Massa G, Optten BJ, De Muink Keizer-Scgrama SM, Delemarrevan de Waal HA, Jansen M, Vulsma T et al. The Dutch growth hormone working group: treatment with two hormone regimens in girls with Turner syndrome: final height results. Hormone Research 199543 144-146.

4 Van den Broeck J, Massa GG, Attanasio A, Matranga A, Chaussain JL, Price DA et al. Final height after long term growth hormone treatment in Turner syndrome. Journal of Pediatrics 1995127 $729-735$. 
5 Heusler G, Schmitt K, Blumel P, Plochl E, Waldhor Th \& Frisch H Growth hormone in combination with anabolic steroids in patients with Turner syndrome: effect on bone maturation and linear height. Acta Paediatrica 199685 1408-1414.

6 Nilsson KO, Albertsson-Wikland K, Alm J, Aronson S, Gustafsson J, Hagenas L et al. Improved final height in girls with Turner's syndrome treated with growth hormone and oxandrolone. Journal of Clinical Endocrinology and Metabolism 199681 635-640.

7 Rosenfeld RG, Attie KM, Frane J, Brasel JA, Burstein S, Cara JF et al. Growth hormone therapy of Turner syndrome: beneficial effect on final height. Journal of Pediatrics 1998132 319-324.

8 Rochiccioli P, David M, Malpeuch G, Colle M, Limal JM, Battin J et al. Study of final height in Turner's syndrome: ethnic and genetic influences. Acta Paediatrica 199483 305-308.

9 Rosenfeld RG, Hintz RL, Johanson AJ, Sherman B, Brasel JA, Burstein S et al. Three-years results of a randomized prospective trial of methinyl human growth hormone and oxandrolone in Turner syndrome. Journal of Pediatrics 1988113 393-400.

10 Fishman A \& Hochberg Z. Growth hormone therapy for Turner's syndrome. Harefuah 1991121 281-285.

11 Ranke MB, Pfluger H, Rosendahl W, Stubbe P, Enders H, Bierich JR \& Majewski F. Turner syndrome: spontaneous growth in 150 cases and review of the literature. European Journal of Pediatrics $198314181-88$.

12 Tanner JM \& Whitehouse RM. Clinical longitudinal standards for height, weight, height velocity, weight velocity and stages of puberty. Archives of Disease in Childhood 197651 170-179.

13 Taback SP, Collu R, Deal CL, Guyda HJ, Slisbury S, Dean HJ \& Van Vliet G. Does growth hormone supplementation affect adult height in Turner's syndrome. Lancet 1996348 25-27.

14 Dacou-Voutetakis C, Karavanaki-Karanassiou K, Petrou V, Georgopoulos N, Maniati-Christidi \& Mavrou A. The growth pattern and final height of girls with Turner syndrome with and without human growth hormone treatment. Pediatrics 1998101 663-668.
15 Lyon AJ, Preece MA \& Grant DB. Growth curves for girls with Turner's syndrome. Archives of Disease in Childhood 198560 932-935.

16 Easterbrook PJ, Berlin JA, Gopalan R \& Matthews DR. Publication bias in clinical research. Lancet $1991337867-872$.

17 Bramswig JH. Expectation bias with respect to growth hormone therapy in Turner syndrome. European Journal of Endocrinology $1997137446-447$.

18 Rochiccioli P \& Chaussain JL. Final height in patients with Turner syndrome treated with growth hormone $(n=117)$. In Turner Syndrome in a Life Span Perspective, pp 123-128. Eds K AlbertssonWikland \& MB Ranke. Amsterdam: Elsevier, 1995.

19 Hochberg Z, Aviram M, Rubin D \& Pollack S. Decreased sensitivity to insulin like growth factor-I in Turner syndrome: a study of monocytes and T-lymphocytes. European Journal of Clinical Investigation 199727 543-547.

20 Sanger R, Tippett P, Gavin J, Teesdale P \& Daniels GL. Xg groups and sex chromosome abnormalities in people of Northern European ancestry: an addendum. Journal of Medical Genetics $197714210-222$.

21 Massa G, Vanderschueren-Lodeweyckx M \& Malvaux P. Linear growth in patients with Turner syndrome: influence of spontaneous puberty and parental height. European Journal of Pediatrics $1990149146-150$.

22 Salerno MC \& Job AC. La taille dans le syndrome Turner correlations avec la taille des parents. Archives Francaises de Pediatrie $198744863-865$.

23 Lampit M, Lorber A, Vilkas DL, Nave T \& Hochberg Z. Growth hormone $(\mathrm{GH})$ dependence and $\mathrm{GH}$ withdrawal syndrome in $\mathrm{GH}$ treatment of short normal children: evidence from growth and cardiac output. European Journal of Endocrinology 1998138 401-407.

Received 10 August 1998

Accepted 25 March 1999 